Fundamentals of Mechanical Vibrations 


\section{Fundamentals of \\ Mechanical Vibrations}

Matthew Hussey

Physics Department,

Dublin Institute of Technology

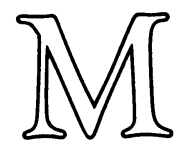


(C) Matthew Hussey 1983

Softcover reprint of the harcover 1st edition 1983

All rights reserved. No part of this publication may be reproduced or transmitted, in any form or by any means, without permission.

First published 1983 by

THE MACMILLAN PRESS LTD

London and Basingstoke

Companies and representatives

throughout the world

Typeset in 10/12 Times by

Photo-Graphics, Honiton, Devon

ISBN 978-0-333-32437-0

ISBN 978-1-349-17070-8 (eBook)

DOI 10.1007/978-1-349-17070-8

The paperback edition of the book is sold subject to the condition that it shall not, by way of trade or otherwise, be lent, resold, hired out, or otherwise circulated without the publisher's prior consent in any form of binding or cover other than that in which it is published and without a similar condition including this condition being imposed on the subsequent purchaser. 
For my Mother and Father 


\section{Contents}

Preface $\quad$ xi

List of Symbols

1 Fundamental Mechanical Quantities 1

1.1 Introduction and Objectives 1

1.2 Force and Torque 1

1.3 Hooke's Law

1.4 Work and Mechanical Energy 13

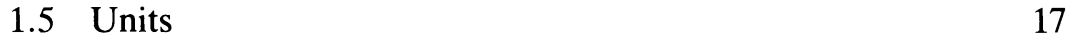

$\begin{array}{lll}1.6 & \text { Experiments } & 17\end{array}$

Problems 20

Further Reading $\quad 22$

2 Free Harmonic Oscillator 23

2.1 Introduction and Objectives 23

2.2 The Simple Harmonic Oscillator 23

2.3 Graphical Display of Simple Harmonic Motion 27

2.4 Forces in the Oscillator 28

2.5 Energy in the System 28

2.6 Initial Conditions 30

2.7 Other Simple Harmonic Oscillators 32

2.8 Electrical analogues of the Simple Harmonic Oscillator 37

2.9 Experiments 40

Problems 41

Further Reading $\quad 43$

3 Damped Free Harmonic Oscillator 44

3.1 Introduction and Objectives $\quad 44$

3.2 Friction and Damping 44

3.3 Damped Harmonic Oscillator 51

3.4 Three Different Types of Behaviour 52

3.5 Energy in the Damped System 58

3.6 Functional Parameters of the Underdamped System 62

3.7 Electrical Analogue Circuits 64 
3.8 Experiments $\quad 66$

$\begin{array}{ll}\text { Problems } & 68\end{array}$

$\begin{array}{ll}\text { Further Reading } & 70\end{array}$

4 Sinusoidal Driving of the Damped Harmonic Oscillator 72

4.1 Introduction and Objectives $\quad 72$

4.2 Sinusoidally Forced Harmonic Oscillator 72

4.3 Mechanical Impedance and Compliance 79

4.4 Energy and Power in the Driven Oscillator 83

4.5 Power Resonance $\quad 87$

4.6 Electrical Analogue Circuits 92

4.7 Experiments 93

Problems $\quad 94$

Further Reading $\quad 96$

5 Harmonic Analysis and Transform Techniques in Damped 97

Harmonic Oscillator Systems

$\begin{array}{lll}5.1 & \text { Introduction and Objectives } & 97\end{array}$

5.2 Fourier Theory of Harmonic Analysis 97

5.3 Truncated Fourier Series 104

5.4 Pulse Trains, Isolated Pulses and Shocks 107

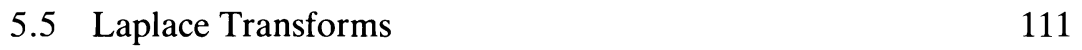

5.6 Linearity and Superposition 116

5.7 Application of Laplace Transform Technique to a Linear $\begin{array}{ll}\text { System } & 117\end{array}$

5.8 Impulse Response and System Transfer Function 119

$\begin{array}{ll}5.9 \text { Experiments } & 124\end{array}$

$\begin{array}{ll}\text { Problems } & 124\end{array}$

$\begin{array}{ll}\text { Further Reading } & 126\end{array}$

6 Coupled Harmonic Oscillators 127

6.1 Introduction and Objectives $\quad 127$

6.2 Coupled Oscillating Systems - Modes 127

6.3 Energy in the Coupled System 134

6.4 Resonances in the Coupled System 136

6.5 Electrical Analogues 139

6.6 Experiments 141

$\begin{array}{ll}\text { Problems } & 142\end{array}$

Further Reading 144

7 Non-discrete-element Mechanical Vibratory Systems 145

$\begin{array}{lll}7.1 & \text { Introduction and Objectives } & 145\end{array}$

7.2 Simple Harmonic Oscillator with Massy Spring 145

$\begin{array}{ll}7.3 \text { Compound Pendulum } & 147\end{array}$ 
$\begin{array}{lll}7.4 & \text { Vibrating String } & 149\end{array}$

7.5 Solid Rod in Transverse or Flexural Vibration 154

7.6 Longitudinal Vibrations in a Solid Rod 159

7.7 Vibrating Circular Membrane 163

$\begin{array}{lll}7.8 & \text { Vibrations in Air Columns } & 168\end{array}$

7.9 Electrical Analogue of Distributed Oscillators 171

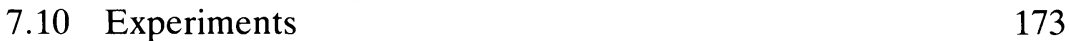

Problems 176

$\begin{array}{ll}\text { Further Reading } & 179\end{array}$

8 The Piezoelectric Effect 180

8.1 Introduction and Objectives 180

8.2 Basic Aspects of the Piezoelectric Effect 180

8.3 The Piezoelectric Relationships 182

8.4 Alternative Forms of the Piezoelectric Relationships 185

8.5 Wave Equation in a Piezoelectric Slab 190

$\begin{array}{lll}8.6 & \text { Experiments } & 197\end{array}$

Problems 197

Further Reading 198

9 Non-linear Vibratory Systems 199

$\begin{array}{ll}9.1 \text { Introduction and Objectives } & 199\end{array}$

9.2 Non-linear Spring 199

9.3 Non-linear Spring and Mass under Harmonic External Force 204

9.4 Non-linear Damping in a Freely Vibrating Simple Oscillator 207

9.5 Oscillator with Hysteretic Damping under Harmonic Force 211

9.6 Static Friction Damping in an Oscillator 214

$\begin{array}{lll}9.7 & \text { Experiments } & 217\end{array}$

$\begin{array}{ll}\text { Problems } & 219\end{array}$

Further Reading 220

10 Vibration Measurement and Analysis 222

10.1 Introduction and Objectives 222

10.2 Effects of Vibrations in Mechanical Systems 222

10.3 Measurement Equipment 224

10.4 Vibration Transducers, Accelerometer and Vibrometer 225

10.5 Other Displacement, Strain and Force Transducers 231

10.6 Analysis of Periodic Vibrations 233

10.7 Random Vibrations 235

10.8 Shocks/Pulsed Vibrations 244 
10.9 Experiments 244

Problems 245

Further Reading $\quad 247$

11 Vibration Isolation and Control 248

11.1 Introduction and Objectives 248

11.2 Sources of Vibrations 248

11.3 Vibration Prevention 250

11.4 Isolation of Vibration Source 252

11.5 Protection of Equipment against Vibrations 257

11.6 Dynamic Vibration Absorbers 258

11.7 Experiments 263

Problems $\quad 264$

Further Reading 266

12 Vibrations and the Human Body 267

12.1 Introduction and Objectives 267

12.2 Effects of Mechanical Vibrations on Human Beings 267

12.3 The Body as a Mechanical System 272

12.4 Ballistocardiography 274

12.5 Pulsatile Wave Propagation along Arteries in the Body 276

12.6 Experiments 281

Problems 282

Further Reading $\quad 284$

Answers to Problems 283

Index 293 


\section{Preface}

A knowledge and appreciation of mechanical vibrations are fundamental to wide areas of physics, engineering and architecture. Naturally occurring vibrations are of interest to geophysicists, to civil engineers and to medical physicists. Guarding against the effects of excessive vibrations is a prime concern of design engineers, architects, civil engineers, structural and mechanical engineers, instrumentation physicists and biomedical engineers. The design and construction of vibrating machines is often the aim of mechanical engineers and acoustic engineers. The measurement and interpretation of vibrations are important tasks for maintenance engineers and physicists.

The aim of this book is to provide the basic groundwork in mechanical vibrations for these various disciplines. Practice in problem-solving is probably the single most powerful mechanism for learning and therefore it is strongly recommended that the student attempt all of the problems appended to each chapter. The value of the text will be greatly enhanced if its study is accompanied by a course of related laboratory experiments. Each chapter has a list of suggested laboratory exercises relating to the material in that chapter. At the end of each chapter there is a brief list of books for further reference. Whenever possible, the student should consult these in order to supplement and expand on the coverage in this text, to obtain alternative insights, to delve deeper into specific topics and to find additional problems.

Students embarking on this book should have the following prerequisites: differential and integral calculus, including partial differential equations; physics to approximately first-year college level; A.C. electricity, which could be studied concurrently; mechanical properties of materials, which could also be studied concurrently.

Thanks are due to Ms Elema Flanagan for doing much of the art work and to Ms Gerardine Keating for typing the first draft.

MATTHEW HUSSEY 


\section{List of Symbols}

$A$ area $\mathrm{m}^{2}$

amplitude constant -

a amplitude constant -

radius $\mathrm{m}$

$\alpha \quad$ coefficient of decay or decay constant $\quad 1 / \mathrm{s}$

attenuation constant $1 / \mathrm{m}$

$B$ amplitude constant -

bulk modulus of elasticity $\quad \mathrm{Pa}$

$b \quad \begin{aligned} & \text { damping coefficient } \\ & \text { amplitude constant }\end{aligned}$

$\beta$ propagation or wavelength constant $1 / \mathrm{m}$

$C$ spring constant $\mathrm{N} / \mathrm{m}$

amplitude constant -

electrical capacitance $\mathrm{F}$

inverse of compliance per metre of tube wall $\quad \mathrm{Pa} / \mathrm{m}^{2}$

c amplitude constant

spring constant

speed of propagation

Young's modulus of elasticity

$\mathrm{N} / \mathrm{m}$

$\mathrm{m} / \mathrm{s}$

$\mathrm{N} / \mathrm{m}^{2}$ or $\mathrm{Pa}$

$\mathrm{C} / \mathrm{m}^{2}$

$D$ dielectric displacement

$\mathrm{m}$

amplitude constant

piezoelectric constant

$\delta$ central deflection of beam

$\mathrm{C} / \mathrm{N}$ or $\mathrm{m} / \mathrm{V}$

$\mathrm{m}$

logarithmic decrement -

Dirac delta function

non-linear constant for spring

$\Delta \quad \Delta L$, increment of $L$

$E \quad$ Young's modulus of elasticity

energy

electric field strength or potential gradient

$\mathrm{N} / \mathrm{m}^{2}$ or $\mathrm{Pa}$

$\mathrm{J}$

$\mathrm{V} / \mathrm{m}$

$e \quad$ piezoelectric constant

$\mathrm{C} / \mathrm{m}^{2}$ or $\mathrm{N} / \mathrm{V} \mathrm{m}$

eccentric radius

$\mathrm{m}$

$\epsilon \quad$ dielectric constant

$\mathrm{C} / \mathrm{m} \mathrm{V}$

$F$ force

$\mathrm{N}$

Fourier transform 
$f \quad$ frequency instantaneous force general function

$\varphi$ angular displacement phase angle

$\Phi$ maximum angular deflection

$G \quad$ force divided by mass

Gibbs' free energy amplitude constant

$g$ acceleration due to gravity instantaneous force divided by mass piezoelectric constant mass ratio in dynamic vibration absorber

$\gamma \quad$ end deflection of cantilever phase angle ratio of specific heats of gas complex propagation constant

$H$ heat system transfer function enthalpy amplitude constant

$\dot{H}$ rate of heat production

$h$ height impulse response piezoelectric constant hysteretic damping coefficient

$\eta \quad$ coefficient of viscosity

I mass moment of inertia area moment of inertia electrical current

$i$ instantaneous electrical current

$i$ rate of change of electrical current

$J$ Bessel function electrical current density

$$
\text { j } \quad V-1
$$

$K$ constant integer

$k$ constant integer coupling coefficient of piezoelectric material

$x \quad$ mass per unit length of string compliance or compressibility non-linearity constant of spring
$\mathrm{Hz}$

$\mathrm{N}$

$\mathrm{rad}$

$\mathrm{rad}$

$\mathrm{rad}$

$\mathrm{m} / \mathrm{s}^{2}$

J

$$
=9.81 \mathrm{~m} / \mathrm{s}^{2}
$$

$\mathrm{m} / \mathrm{s}^{2}$

$\mathrm{m}^{2} / \mathrm{C}$ or $\mathrm{V} \mathrm{m} / \mathrm{N}$

$\mathrm{m}$

$\mathrm{rad}$

$1 / \mathrm{m}$

J

J

$\mathrm{Pa}$

$\mathrm{J} / \mathrm{s}$

$\mathrm{m}$

$\mathrm{N} / \mathrm{C}$ or $\mathrm{V} / \mathrm{m}$

$\mathrm{N} / \mathrm{m}$

$\mathrm{kg} / \mathrm{s} \mathrm{m}^{2}$

$\mathrm{kg} \mathrm{\textrm {m } ^ { 2 }}$

$\mathrm{m}^{4}$

A

A

$\mathrm{A} / \mathrm{s}$

$\mathrm{A} / \mathrm{m}^{2}$

J

$=1,2,3 \ldots$

$=0,1,2 \ldots$

$\mathrm{kg} / \mathrm{m}$

$\mathrm{m}^{2} / \mathrm{N}$ 
L angular momentum

length

electrical inductance

Laplace transform

$\mathscr{L} \quad$ Laplace transform operation

$\mathscr{L}^{-1}$ Inverse Laplace transform operation

$l \quad$ length

integer

$\lambda \quad$ wavelength

$M$ mass

bending moment or torque

$m$ integer

$\mu \quad$ coefficient of static friction mass per unit area of membrane

Mom linear momentum

$N \quad$ Bessel function

$n$ shear modulus of elasticity integer

$P \quad$ power

pressure

amplitude of mode displacement

distribution function

protection factor

p constant

instantaneous power

amplitude constant

mode displacement

instantaneous pressure

initial displacement

probability density

$\dot{p} \quad$ rate of change of instantaneous pressure

$\pi$ constant

$\psi$ phase angle

mode co-ordinate

angular frequency

$\Psi$ amplitude of mode co-ordinate

$Q \quad$ quality factor or value

$2 \times$ spectral density function

$\dot{Q}$ flow rate

q constant

instantaneous electrical charge

damping ratio

amplitude constant

initial velocity

$\stackrel{q}{q}$ instantaneous flow rate $\mathrm{kg} \mathrm{m}^{2} \mathrm{rad} / \mathrm{s}$

$\mathrm{m}$

H

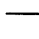

-

m

$=0,1,2 \ldots$.

m

$\mathrm{kg}$

$\mathrm{N}$ m

$=0,1,2 \ldots$

$\mathrm{kg} / \mathrm{m}^{2}$

$\mathrm{kg} \mathrm{m} / \mathrm{s}$

$\mathrm{N} / \mathrm{m}^{2}$ or $\mathrm{Pa}$

$=0,1,2 \ldots$

W

$\mathrm{Pa}$

m

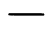

m

W

$\mathrm{m}$

$\mathrm{Pa}$

$\mathrm{m}$

$\mathrm{Pa} / \mathrm{s}$

$=3.14159 .$. .

$\mathrm{rad}$

$\mathrm{m} \mathrm{kg}^{1 / 2}$

$\mathrm{rad} / \mathrm{s}$

$\mathrm{m} \mathrm{kg}^{1 / 2}$

-
$\mathrm{m}^{3}$
$\mathrm{~m}$

$\mathrm{m}^{3} / \mathrm{s}$

C

-

$\mathrm{m} / \mathrm{s}$

$\mathrm{m}^{3} / \mathrm{s}$ 
$R \quad$ electrical resistance $\quad \Omega$ radial distance $\mathrm{m}$ universal gas constant $\quad=8.31 \mathrm{~J} / \mathrm{mole} \mathrm{K}$

$r$ radius $\mathrm{m}$ radial axis ratio of frequency to natural frequency

$\rho$ density resistivity

$S \quad$ strain spectral density function

$s \quad$ circumferential displacement m transform parameter ratio of third to first harmonic amplitudes circumferential velocity circumferential acceleration

$\mathrm{m} / \mathrm{s}$

$\mathrm{m} / \mathrm{s}^{2}$

$\sigma$ force per unit length of periphery of membrane entropy

$\mathrm{N} / \mathrm{m}$ standard deviation

$T \quad$ stress period of oscillation or of periodic function $\mathrm{J} / \mathrm{K}$ transmissibility

$t$ time temperature

$\tau$ time constant or relaxation time duration of pulse

$\mathrm{kg} / \mathrm{m}^{3}$

$\Omega \mathrm{m}$
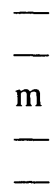

一

-

$\mathrm{N} / \mathrm{m}^{2}$ or $\mathrm{Pa}$

$\mathrm{s}$

s

${ }^{\circ} \mathrm{C}$

$\mathbf{s}$

s time variable $s$

$\vartheta$ angular displacement $\mathrm{rad}$ angle angular axis in cylindrical co-ordinates absolute temperature angular velocity angular acceleration

$\operatorname{Tr}$ torque or turning moment

$U$ step function internal energy

$V \quad$ volume electrical potential difference

$v \quad$ instantaneous potential difference

$w$ distance

$\omega$ angular velocity or angular frequency

Wk work

$X \quad$ Laplace transform of $x$

$x \quad$ axis

displacement along $x$-axis

$\mathrm{rad}$

$\mathrm{K}$

$\mathrm{rad} / \mathrm{s}$

$\mathrm{rad} / \mathrm{s}^{2}$

$\mathrm{N} \mathrm{m}$

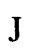

$\mathrm{m}^{3}$

$\mathrm{V}$

$\mathrm{V}$

$\mathrm{m}$

$\mathrm{rad} / \mathrm{s}$

$\mathrm{N}$ m or $\mathbf{J}$ change in length of spring 
velocity in $x$-direction

$\mathrm{m} / \mathrm{s}$

$x$ acceleration in $x$-direction

$\mathrm{m} / \mathrm{s}^{2}$

particle displacement along $x$-axis

$\mathrm{m}$

particle velocity along $x$-axis

$\mathrm{m} / \mathrm{s}$

particle acceleration in $x$-direction

$\mathrm{m} / \mathrm{s}^{2}$

mechanical compliance

$\mathrm{s} / \mathrm{kg}$

$y \quad$ axis

displacement along $y$-axis

m

distance

$\mathrm{m}$

velocity along $y$-direction

$\mathrm{m} / \mathrm{s}$

acceleration along $y$-direction

$\mathrm{m} / \mathrm{s}^{2}$

$Z$ mechanical impedance

$\mathrm{kg} / \mathrm{s}$ or $\mathrm{N} \mathrm{s} / \mathrm{m}$

electrical impedance

$\Omega$

axis

displacement along $z$-axis

$\mathrm{m}$

velocity along $z$-axis

acceleration along $z$-direction

$\mathrm{m} / \mathrm{s}$

particle displacement along $z$-axis

$\mathrm{m} / \mathrm{s}^{2}$

particle velocity in $z$-direction

$\mathrm{m}$

particle acceleration in $z$-direction

$\mathrm{m} / \mathrm{s}$

$\mathrm{m} / \mathrm{s}^{2}$ 